\title{
Opportunistic versus life-cycle-oriented decision making in multi-loop recovery: an eco-eco study on disposed vehicles
}

\author{
Harold Krikke
}

Received: 1 December 2009 / Accepted: 5 June 2010 /Published online: 9 July 2010

(C) The Author(s) 2010. This article is published with open access at Springerlink.com

\begin{abstract}
Purpose Multinational companies have recently been encouraged by government policies to implement Extended Producer Responsibility. One objective is to stimulate high-level recovery, and the other is to introduce life cycle thinking. This paper studies decision making in recovery, comparing opportunistic decision making with short-term profit maximization (usually leading to one loop) versus a life-cycle perspective (leading to multiple loops). The question is (1) which business benefits this brings as well as reduction of environmental impact and (2) whether companies should be inclined to think multi-loop and if so how governments could stimulate this.

Methods After comparing the problem with the literature, a non-linear optimization model is presented optimizing NPV of revenues and calculating environmental impact with cumulative energy demand and cumulative recovery rates. The environmental indicators chosen are motivated based on literature research in the area of streamlined LCA. Sensitivity analysis tests solutions on various sources of uncertainty. We study a real-life case with real data.

Results and discussion Based on the results, we can formulate the following insights for industry. Firstly, cascade markets for reuse may appear attractive but new sales cannibalization compromised margins. To neutralize this effect, returns should be remanufactured to equal-to-new quality hence no difference should exist between new and recovered items. Companies must suppress their natural
\end{abstract}

Responsible editor: Wulf-Peter Schmidt

\section{H. Krikke $(\square)$}

CentER, Tilburg University,

5000 LE,

90153 Tilburg, the Netherlands

e-mail: krikke@uvt.nl instincts of maximizing short-term profits and delay some of the revenues by implementing multi-loop models in order to maximize total life-cycle profit. Environmental impact improves as well according to both indicators. Feasibility of returns should be maximized which for example implies careful collection and storage of wrecks, preventing damage and corrosion, etc. Product design changes may further enhance feasibility. However, the concept requires that all loops are controlled well by one actor. For governments the following advices apply. As mentioned, most EPR-based systems in place today maximize single loop 3. Using alternative steering principles instead of target quota on recovery and collection could stimulate multi-loop solutions that prove more robust, more profitable, and have better footprint.

Conclusions It is concluded that multi-loop recovery is preferred both economically and environmentally. But both industry and governments must improve their policies. Therefore, future research is mapped based on handles and delineations of the study.

Keywords Automotive case study - Disposition . Environmental impact $\cdot$ Legislation $\cdot$ Life cycle .

Net present value $\cdot$ Streamlined LCA

\section{Introduction}

Multinational companies have recently been encouraged by government policies based on extended producer responsibility (EPR). EPR is defined as "a policy approach in which producers accept significant responsibility, financial and/or physical, for the treatment or disposal of products" (OECD 2001). EPR policies have two distinct objectives: the realization of high-quality recovery of returns and the 
provision of incentives for producers to include environmental considerations in the design of their products, resulting in a life-cycle approach.

A key decision in EPR is choosing the right recovery option. Thierry et al. (1995) present recovery options on a conceptual level: direct reuse, repair, refurbishment, and remanufacturing concern reuse "as is" with potential upgrade, harvesting refers to reuse parts/components retrieved, and material recycling applies when the return is shredded. Incineration is often used for energy recovery.

From a life-cycle perspective, it is crucial that the feasibility of recovery options is sequential in time. Reuse options are more feasible when the returned item is still in reasonable condition and still wanted in the market, first as a product, later as a component. Once obsolete or beyond repair, material recycling can be applied. As a final option, incineration combined with energy recovery is applicable. Skipping an option means removing this possibility for the future. Figure 1 distinguishes three hierarchical recovery loops and energy recovery on a conceptual level, based on Krikke et al. (1998).

However, industry tends to maximize revenues opportunistically on the short term (Mayers 2001), whilst EPR-based governments primarily impose single-loop material recycling (Zoeteman et al. 2010). We claim it is better, both economically and environmentally, to go for multi-loop optimization.

This paper studies the effects of opportunistic decision making, maximizing revenues of the first loop, versus lifecycle optimization on total time-based profit. The basic trade-off is to take the maximum short-term profit now possibly destroying future revenues, or to delay revenues into the future, accepting lower proceeds now.

We model the problem by a decision tree with timesequential, hierarchical recovery options, allowing for the possibility of (permanently) skipping options. Using that decision tree, we show that routes based on life-cycle profits are superior. We calculate environmental impact as a spin of result, using cumulative energy use (cumulative energy demand (CED)) and cumulative recovery scores as environ- mental indicators. We will show that the environment benefits from a multi-loop approach as well.

Our model can be best described as eco-eco, trading of environmental and economical objectives. Our methodological choices, in particular using streamlines life cycle assessment (LCA), will be motivated using results from the literature, including limitations of the research. We apply our model to a real-life case, concerning the car wreck recycling under EPR. Next to the base case, we conduct sensitivity analysis to test robustness of solutions, a technique often used in life-cycle studies. For example, there is always to fear of cannibalizing on new market sales when returns are recovered for cascade markets (Guide and Van Wassenhove 2001). Related uncertainties include the profitability of new parts, which impacts the viability of parts reuse. A similar uncertainty lies in recycling as scrap market prices jump up and down. Another category of uncertainty is feasibility of recovery options due to technical quality or market (acceptance) constraints (Krikke et al. 1998). Finally, we address the impact of EPR recovery targets.

The setup of this paper is as follows. Section 2 discusses papers that present relevant models on eco-eco modeling, automotive applications, and time-based value of money. Section 3 discusses the case study and our model. Section 4 presents results, discusses them and gives recommendations to industry and policy makers. Section 5 draws conclusions.

\section{Literature}

\subsection{Literature on disposition models}

There is abundant literature on disposition in general, see reviews of Gungor and Gupta (1999), Srivastava (2007), Ilgin and Gupta (2010) and the survey on disassembly sequencing by Lambert (2003).

As part of their review, Ilgin and Gupta (2010) provide references in multi-criteria decision support for end-of-life (EOL) support. Combined approaches, referred to as eco-

Fig. 1 Multi-loop applications of recovery options (general)

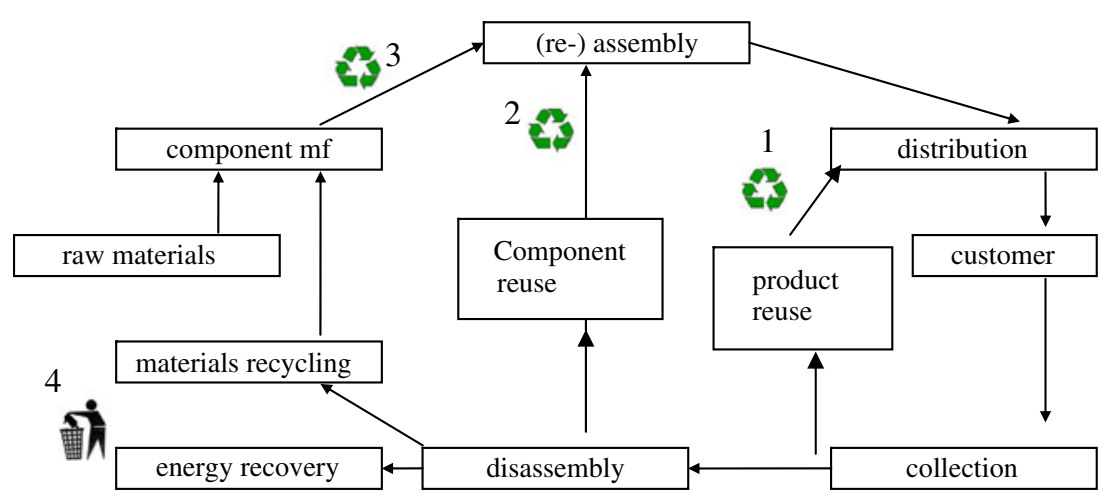


eco models, are relatively rare. Some of them focus on support of product development, e.g., Zuidwijk and Krikke (2008) and Gehin et al. (2008). Hula et al. (2003), Iakovou et al. (2009), Staikos and Rahimifard (2007) develop multicriteria tools for EOL decision making. Bloemhof-Ruwaard et al. (1996), Hammond and Beullens (2007), Krikke et al. (2003), Quariguasi Frota Neto et al. (2008), Quariguasi Frota Neto et al. (2009) also apply eco-eco models using various mathematical techniques in various industries. Kerr and Ryan (2001) discuss a copier remanufacturing case at Fuji Xerox Australia, showing the many economical and environmental benefits of remanufacturing besides material savings Michelsen et al. (2007) evaluate six different product designs of furniture for different end-of-life in what they call the extended supply chain, what is in fact the recovery option. Some of them apply mathematical techniques. Spengler et al. (2003) present a mixed integer programming models that coordinates decision on product acquisition, disassembly and recycling in electronics. All models discussed deal with single-loop optimization.

More specific in automotive, Williams et al. (2007) present a study that looks at the impact changing vehicle designs on the profitability of shredding and recycling process. Moreover, the model determines whether to ship light non-ferrous and heavy ferrous separately or mixed. They consider the option of multiple loops of one recovery option in automotive, namely material recycling, thereby maximizing profit. The model does not consider reuse. Ferrao and Amaral (2006) study economics of recycling system under increasing quota. Although there results are reassuring for industry, the model is rather simplistic. Both models ignore environmental impact other than compliance. Schmidt et al. (2004) apply streamlined LCA to study the impact of various end-of-life options and weight-reduction scenarios. In view of our research, an important conclusion is that varying EOL technologies (all recycling based) have little significance. None of the automotive models found in the literature applies a multi-loop, multi-option perspective.

Further intensive literature research revealed no papers that considered multi-loop hierarchical recovery options, neither in the automotive business nor elsewhere.

\subsection{Literature on (environmental) performance measures}

We aim to optimize different recovery options over the lifecycle including both environmental and economical objectives. In order to model this problem life cycle based, we must take into account the time-based value of money. We argue that net present value (NPV) is the soundest basis for long term strategic supply chain decision making. NPV is defined as the total discounted cash-flow over an infinite horizon. In reverse logistics, NPV is mostly applied in models with inventory management and repair. For defi- nitions and overview of NPV models in reverse logistics we refer to van der Laan (2003).

Modeling costs in supply chain may be relatively straightforward, great care needs to be taken on the environmental footprint (Hunt et al. 1998). The ecological footprint in general is a measure of human demand on the Earth's ecosystems in relation to its capacity to regenerate. While ecological footprints, e.g., carbon footprints, are becoming more fashionable in business, they cannot be considered as an alternative to LCA, in fact they need one as input.

A simplified LCA is often carried out to keep data collection manageable. Whether or not this is acceptable depends on two major considerations. Firstly, it depends on the purpose of this study. In closed loop supply chains it is generally not the goal to determine the environmental impact of an entire product system, but to screen the impact of different end-of-life recovery options. It is often not possible to find specific data on this process in the wellknown LCA databases. Secondly, the challenge is to find a good screening indicator for the study at hand. CED is mentioned in the literature as a reliable screening indicator for energy-related impacts; see Fleischer et al. (2001) and Huijbregts et al. (2006). It correlates strongly to global warming and greenhouse gasses and it also enhances reduction of energy intensive processes. Energy reduction is very important in recovery. Energy needed for closed loop remanufacturing amounts in many cases to only $15 \%$ to $20 \%$ of the amount needed for production of new products (Hauser and Lund 2003). In order not to miss other environmental impacts, such as resource depletion, water use, landuse, or toxicity, we may have to include other indicators as well. The use of energy and mass balances for simplified LCAs is rather common for closed loop supply chain studies (Krikke et al. 2003).

Conversion of (simplified) LCA results into a generic overall measure is another issue debate. The global footprint method translates LCA results into how much bio-productivity is needed. The consumption of energy, biomass, building material, water and other resources (in particular relevant here are land and raw materials) are converted into a normalized measure of land area called "global hectares". Today, calculation standards are now emerging to make results more comparable and consistent, yet there is always discussion on scope, accuracy, etc.

\subsection{Contribution of the paper and delineations}

This paper contributes to the literature by applying NPVbased approaches in a multi-loop recovery optimization, combined with CED and cumulative recovery rate totalized over the product life cycle as environmental indicators. Castro et al. (2003) find, in line with previous studies, that the largest environmental impact of the passenger vehicle's 
life cycle occurs in the use phase-over $90 \%$ - due to the combustion and depletion of fossil fuels. But, important to this paper: also in the other life-cycle phases, the use of fossil fuels is the dominant impact, even for the production phase. Resource depletion due to the use of the materials employed in the vehicle causes a comparatively lower environmental impact, due to the high recovery rate and efficiency of the metallurgical recycling, that balances for about $30 \%$ the total impacts of the materials production and use. Paradoxically, removing or changing the reverse supply chain brings back its relevance. In addition, landfilling as part of recovery options might make it relevant to add land use as relevant indicator, however this is not the applicable to the case at hand since incineration and energy recovery apply as ultimate option. Water use is also negligible. Toxicity is certainly an issue in car wreck recovery, but as it is a similar step in all options, it is left out of the analysis. To avoid conversion issues it was decided to use the measures energy and material separately as indicators. Because $\mathrm{CO} 2$ is related to energy and material use, we do not consider this indicator separately. In fact it can be considered as an example of a footprint.

We apply material flow analysis - measures the flow of materials from source, through the supply chain and back, with multiple routes in the reverse supply chain. Our approach is simplified is two ways: reduction of processes (only EOL options) and reduction of indicators measures. But at the same time, we measure very specifically three recovery options in this multi-option approach, using data retrieved from the (reverse) supply chain itself. Moreover, we add economical data to the model to enable eco-eco trade-offs.

\section{Case study and model}

In the beginning of the 1990s, concern for the environment was growing. Cars were considered to be one of the largest polluters in modern society. The Dutch ministry of housing, spatial planning and the environment came up with the idea of a recycling fee for new cars. Money should be deposited into a special fund managed by the automotive industry, represented by the Dutch society of automobile importers. In 1993, the Dutch automotive business decided to take responsibility for end-of-life vehicles and set up a national recycling system.

Since 1995 almost 2.5 million cars have been recycled through the system, a countrywide network of 270 ELVdismantlers, and dozens of recycling firms. Legislation requires the reporting of a so-called mass balances, showing the relation between inputs and outputs, and thereby the achieved recycling quota with the achievement of this recycling target of $85 \%$ already in 1998 . For more detail, see Le Blanc (2006).

\subsection{Case description}

In this particular case disposed vehicles are returned to the retailer as part of mandatory regulation. From here, the cars are returned to a recovery facility. There are three recovery options available, as shown in Fig. 2. Two of them involve manual disassembly. In the first option, a number of the released parts are reused (including many metal parts) and the remaining metals are recycled. In the second option, only material recycling is applied to all parts. In the third option, no disassembly takes place but metals (ferrous and non-ferrous) are separated after shredding and the rest is incinerated with energy recovery. Mixed allocation of these options is possible, which we will address later on. For the sake of analysis we presume binary options only in the first subsections.

Option 1 extends the life cycle by 2 years, due to parts reuse in the car repair business. Material recycling re-enters the manufacturing system and hence option 2 extends the life cycle with 10 years. Option 3 in our model does not re-enter the original supply chain because we assume that some downgrading applies to metal recycling and incineration supplies to the open energy market. Moreover, a fourth loop (and beyond) could be possible but for simplicity we restrict ourselves to three loops. In line with reality, we also assume that all options are compliant with EPR legislation.

In the base case it is assumed that $50 \%$ cannibalization of new sales occurs through parts reuse and that new sales have a $70 \%$ higher profit margin, where new prices double reuse prices. Costs are incurred with disassembly, shredding and post-shredding separation, and in processing. Reuse of parts is assumed "as is" after disassembly with negligible processing. Energy is used in all processes, but due to substitution all recovery has a negative CED (hence generates energy). Recovery quota is positive and between $70 \%$ and $99 \%$ for loop, but cumulative recovery quota exceed $100 \%$ in multi-loop situations. Revenues come from reuse, recycled materials, and energy recovery. Sometimes there is a net profit, sometimes a net cost. All economical and energy functions are linear.

Data was taken from sources regarding in the car recycling industry. Confidential data are left out. For comparison and validation, data on cars were checked with Castro et al. (2003), Ferrao and Amaral (2006), Schultman et al. (2006), Spielmann and Althaus (2007). In sensitivity, analysis data are adjusted for either uncertainty in some parameters or expected future developments.

NP represents immediate net profit, calculations are as follows.

$$
\begin{aligned}
\mathrm{NP}(\text { option } 1):= & \text { revenues of reused parts } \\
& + \text { revenues of metals recycling }(25 \%) \\
& - \text { disassembly cost minus processing cost } \\
& \text { minus lost profit on new sales }
\end{aligned}
$$


Fig. 2 Return processes and recovery options in case study

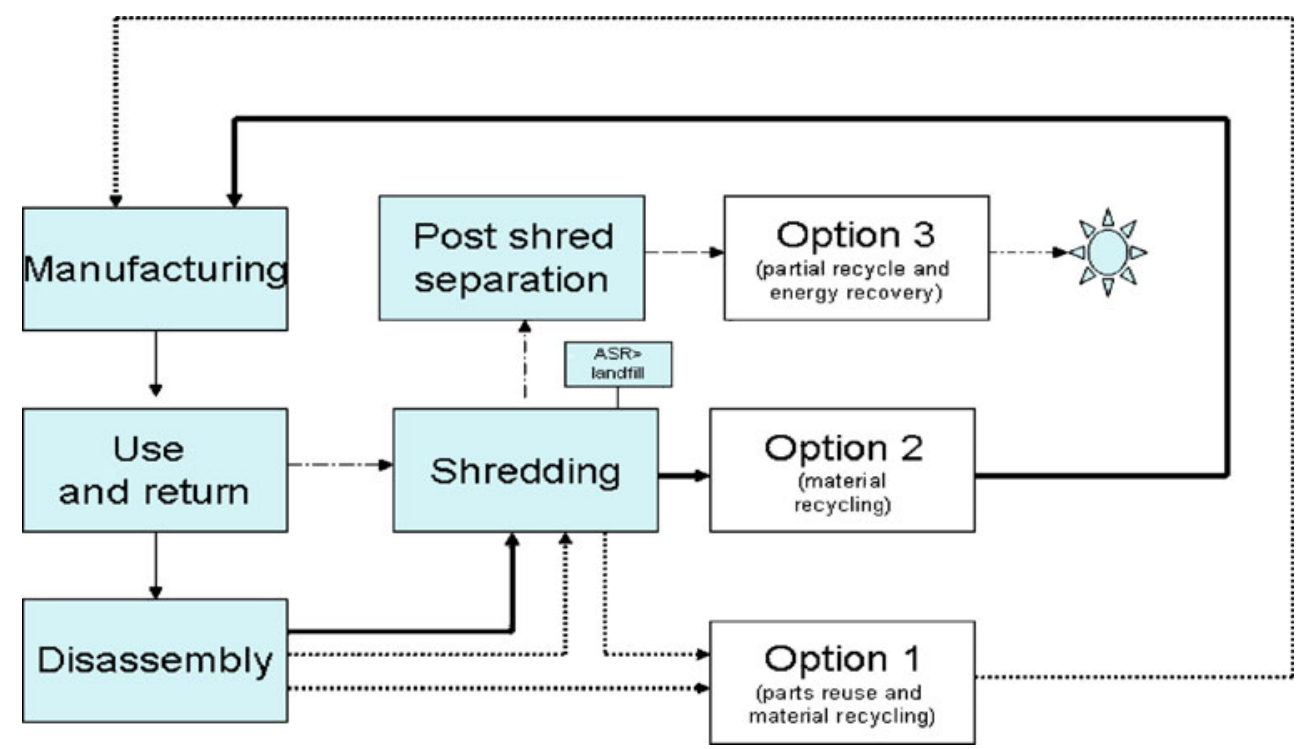

$\mathrm{NP}($ option 2$)=$ revenues of metals recycling $(100 \%)$ minus disassembly cost minus shredding cost minus processing cost of other materials

$\mathrm{NP}($ option 3$)=$ revenues of metal recycling $(100 \%)$ minus shredding cost minus separation cost plus . revenues of energy minus incineration cost

Table 1 summarizes the data used. Option 3 appears very profitable as scrap prices soar and no disassembly (cost) apply. Option 1 is profitable too but much money is lost due to the cannibalization of new sales. Option 2 is close to option 3 in terms of revenues. CED is calculated as the sum of all energy needed in disassembly, processing, shredding, and separation minus energy generated through energy recovery (option and minus energy saved by preventing new production of parts and materials by reuse and recycling, the earlier mentioned substitution effect.

In option 2, for example, energy benefits of metal recycling are exploited. Overall, all options save energy compared with a supply chain without recovery hence CED is negative. Recovery quota is the sum of volumes allocated to reuse and recycling, hence energy recovery is excluded. Note that energy recovery is still feasible from a legislative quota perspective.
We recall that options are hierarchical in the sense that their sequence is fixed. Skipping an option is possible but there is no second change. Figure 3 represents 7 scenarios in which one, two, or all three recovery options are applied.

The decision tree in Fig. 3 represents which routes can be followed per loop and in which way the 7 scenarios can be realized. Note that, e.g., going into reuse in the first loop almost half the scenario's (namely 1,2, and 5) are excluded. The number of loops varies per scenario.

Also note that environmental optimally routes may differ from profit optimal but that ultimately the aim is to let them concur with NPV optimum routes by giving incentives or removing barriers. We will come back to this in the results.

NPV is calculated taking an interest rate $r$ for ROI. Generally speaking, the following formula applies, where + years represents the extension of the life cycle in years when option 2 or 3 is applied.

$\mathrm{NPV}=\mathrm{NP}(1)+\mathrm{NP}(2) /(1+\mathrm{r})^{+ \text {years }}+\mathrm{NP}(3) /(1+\mathrm{r})^{+ \text {years }}$

To ease the understanding, Table 2 represents the calculations, taking $r$ at 3\% annually.

Life cycle profits are totalized profits per loop. Immediate profit refers to the profit of the option first applied. The model compares (immediate) profit of the first loop with the totalized profit over the product life cycle (PLC). It

Table 1 Net profits and net energy per option

\begin{tabular}{lllll}
\hline & NP & CED reduction & Recovery percentage excl. energy recovery & Life cycle \\
\hline Option 1 & $102 €$ (assuming 50\% cannibalization) & -121 GJ & 99 & +2 year \\
Option 2 & $344 €$ & -42 GJ & 97 & +10 years \\
Option 3 & $393 €$ & -38 GJ & 70 & Ends \\
\hline
\end{tabular}


Fig. 3 Decision tree

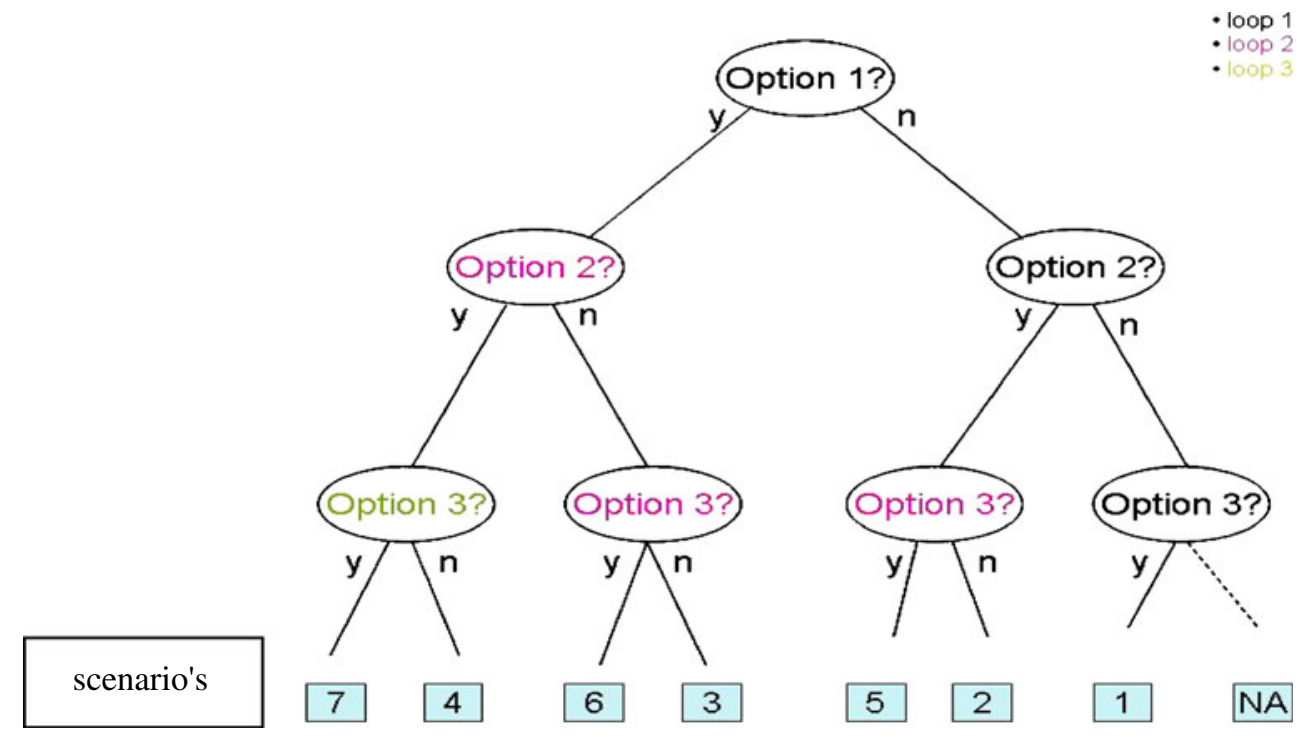

chooses the optimal route in the decision tree from both angles (short term versus long term). Similarly it calculates CED and (cumulative) recovery rates, as a percentage of initial production and sales, for all scenarios. Environmental impact is presumed not to be subject to inflation.

\subsection{A non-linear programming model}

Now, we introduce Boolean (0.1) ya-b, where "a" represents the option chosen and "b" stands for the loop number. So for example y3-3 is set 1 when option 3 is applied in the third loop. This happens only in scenario 7 . In scenario $1, \mathrm{y} 3-1$ is set 1 . In case options do not apply in a certain scenario, the Boolean value is set to zero. In this way, we are able to program the nonlinear model in optimization software. The objective function for the full life cycle reads (restricted to profit):

$$
\begin{aligned}
& \mathrm{y} 1 * \operatorname{NPV}(1)+\mathrm{y} 2 * \mathrm{NPV}(2)+\mathrm{y} 3 * \operatorname{NPV}(3)+\mathrm{y} 2 \\
& -2 * \operatorname{NPV}(2)+\mathrm{y} 3-2 * \mathrm{NPV}(3)+\mathrm{y} 3-3^{*} \mathrm{NPV}(3)
\end{aligned}
$$

where NPV value depends on the scenario chosen, see Table 2.

Depending on decision maker, the full or partial objective function decides which route to follow in the

Table 2 NPV of scenarios (in euro)

\begin{tabular}{llll}
\hline Scenario \# & Option 1 & Option 2 & Option 3 \\
\hline 1 & & & 393 \\
2 & & 344 & \\
3 & 102 & & \\
4 & 102 & $344 \times 1 /(1.03)^{2}$ & $393 \times 1 /(1.03)^{10}$ \\
5 & & 344 & $393 \times 1 /(1.03)^{10}$ \\
6 & 102 & & $393 \times 1 /(1.03)^{12}$ \\
7 & 102 & $344 \times 1 /(1.03)^{2}$ & \\
\hline
\end{tabular}

decision tree, hence the title opportunistic (short term) or life-cycle-based (long term) decision making. Environmental impact is calculated as a spin of result and is the linear function of decision variables, as follows.

$$
\begin{aligned}
& \mathrm{y} 1 *(-121)+\mathrm{y} 2 *(-42)+\mathrm{y} 3 *(-38)+\mathrm{y} 2-2 *(-42) \\
& \quad+\mathrm{y} 3-2 *(-38)+\mathrm{y} 3-3 *(-38)
\end{aligned}
$$

Cumulative and recovery percentage similar by multiplying Booleans by $99 \%, 97 \%$, and $70 \%$ scores respectively for options 1,2 , and 3 .

In the first results, the values are Boolean and set 0 or 1 . Later on, we relax this assumption. We will test in sensitivity analysis the robustness of solutions to cannibalization effects in new markets (option 1), and the prices of scrap (options 2 and 3). For market or quality reasons returns are not always feasible for recovery options. Returns are often classified (Guide and Van Wassenhove 2001; Krikke et al. 1998). In many models the impact of feasibility linearly and sensitivity analysis does not yield very surprising results. However, in a multi-loop situation things are not that obvious because of non-linearity. Feasibility is generally modeled as a factor between 0 (no feasibility) and 1 (full feasibility).

We now introduce $\gamma \mu$ and $k$ as feasibility factors for options 1,2 , and 3 , respectively. Note that $1-\mathrm{K}$ represents the fraction of shredder fluff. Now the decisions taken are no longer Booleans, instead they become fractional allocations, with $0<=$ ya $-\mathrm{b}<=1$.

So in the first loop at most $\gamma$ can be allocated to reuse and the rest $(1-\gamma)$ is immediately forwarded to option 2 (in other words part of the return flow skips reuse). This holds unless NPV of option 1 is lower than of option 2, then reuse is skipped entirely by the return flow.

Table 3 summarizes the upper bound value of decisions. Note that $\mu, \gamma$, and $\kappa$ are assumed constant in time. 
Table 3 Upper bound constraints with restricted recovery feasibility

\begin{tabular}{|c|c|c|c|c|c|}
\hline Loop 1 & & & Loop 2 & & Loop 3 \\
\hline $\mathrm{y} 1 \leq \gamma$ & y2-1 $\leq(1-y 1) \mu$ & 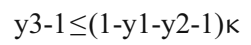 & $\mathrm{y} 2-\leq \mathrm{y} 1 \mu$ & $\mathrm{y} 3-2 \leq 1-\mathrm{y} 2-2 \mathrm{k}$ & $\mathrm{y} 3-3<\mathrm{y} 2-2 \mathrm{k}$ \\
\hline
\end{tabular}

Environmental legislation based on Extended Producer Responsibility impose minimal quota of volumes to be recycled. In practice it means that there is a target on all three options. We model these targets $\mathrm{T}$, often specified per option and increased over time, read loops. We come back to this in the case study.

$$
\begin{aligned}
& \mathrm{y} 1>=\mathrm{T}(1) \\
& \mathrm{y} 2-1>=\mathrm{T}(2-1), \mathrm{y} 2-2>=\mathrm{T}(2-2) \\
& \mathrm{y} 3-1, \mathrm{y} 3-2, \mathrm{y} 3-3>=\mathrm{T}(3-1), \mathrm{T}(3-2), \mathrm{T}(3-3)
\end{aligned}
$$

or combined targets

$\mathrm{y} 1+\mathrm{y} 2-1+\mathrm{y} 3-1>\mathrm{T}^{\prime}$

\section{Results}

In this section, we represent results of the case study. Key is to optimize routes on life cycle using NPV and compare them with immediate profits, assuming that industry is focused on economic results. CED and cumulative recovery rates are calculated for each scenario as well.

\subsection{Base case}

Figure 4 represents results for all seven scenarios. Reading the figure from left to right we see that increasing the number of loops generally improves NPV. However, skipping reuse is attractive because it avoids market cannibalization. Following the intuition of direct profits companies will apply scenario 5 . Scenario 7 is best from an environmental perspective and when following immediate energy gains this scenario will automatically follow. Note that the volume of reuse and recycling exceed the initial sales volume. We conclude that the viability of scenario 7 is hindered by primary market cannibalization. Ironically, much of the energy gains are the results of primary market cannibalization, as reuse is less energy intensive than new production. In the remainder of the paper we compare scenarios 5 and 7 and leave out the others. Single-loop scenarios are excluded because of their immense losses from a PLC point of view, both economically and environmentally.

Scenarios 4 and 6 both have immediate profits lower or equal to scenario 7 and are also excluded. Scenario 7 therefore represents the branch in the decision tree where reuse is applied in the first loop and scenario 5 represents the other branch of the decision tree where reuse is skipped as an option.

\subsection{Sensitivity analysis on substitution and market cannibalization}

Obviously it is a strong assumption that $50 \%$ of the customers transfers from the primary market to the reuse market which sells parts at half the price. Because little research has been conducted into to the actual loss of sales in primary markets due to reuse we have to test this assumption. As scenario 5 does not apply reuse, we only
Fig. 4 Base case results per scenario

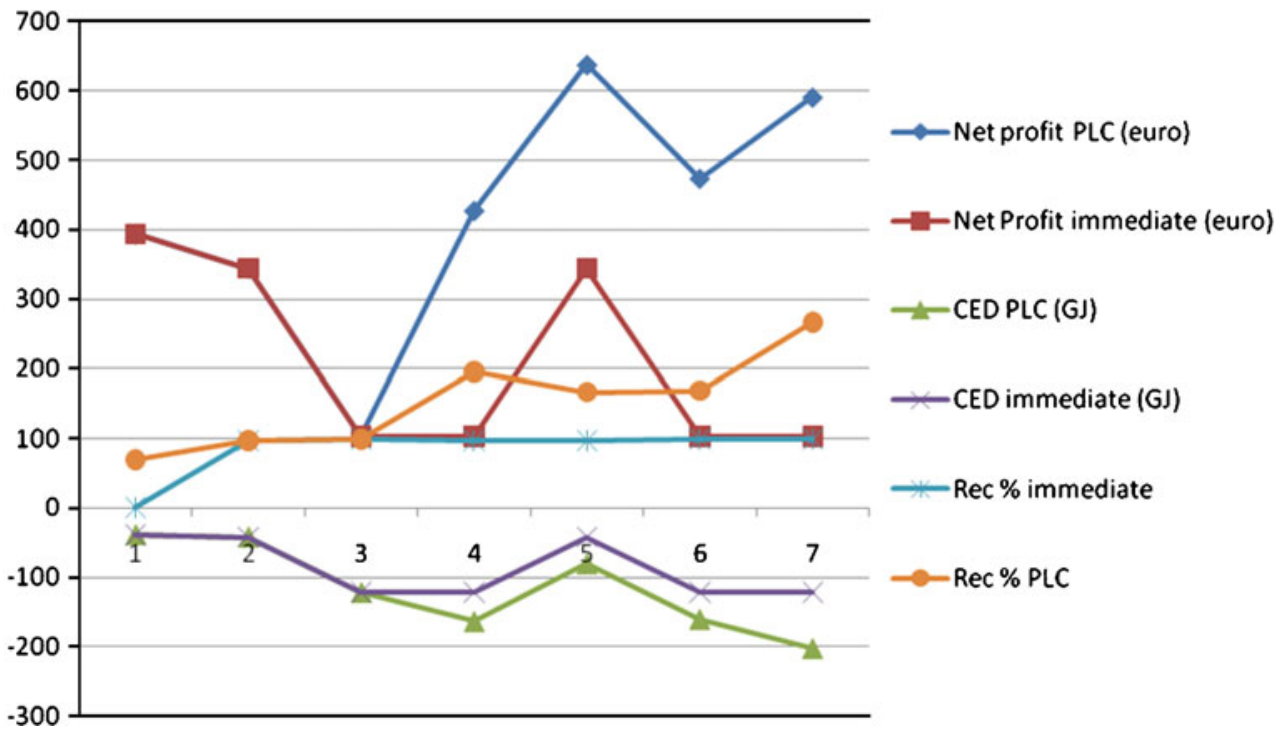


need to vary the degree of cannibalization for scenario 7 . Benchmark values of scenario 5 are plotted in Fig. 5 together with the results of the scenario 7 . Note that when deciding on immediate profits cannibalization has to be reduced to below $20 \%$ to change to scenario 7 . When recovery options are chosen on PLC profit, the breakeven point is around $40 \%$ cannibalization. At all times, reducing cannibalization is profitable.

Cannibalization can be prevented in two ways: do not apply reuse hence skip option 1 or alternatively by remanufacturing. Contrary to reuse "as is", in remanufacturing no difference exists in quality and price of remanufactured and new parts (Thierry et al. 1995). Reuse is "invisible" to the market. Consequently market cannibalization disappears, but substitution still exists. Revenues on reuse increase, so do (remanufacturing) cost, but generally margin improve (Hauser and Lund 2003). In the next section, we assume that reuse has equal-to-new quality.

\subsection{Sensitivity on relative profitability of new parts}

Assuming that reuse parts are equal-to-new quality and hence are sold at new prices eliminates the issue of cannibalization as new and reuse markets concur. The reverse chain now serves as a supplier of parts. Spares can be sourced from reuse or new; and the choice depends solely on the relative margin. Given that we know the margin on reused parts from our dataset, we now vary the margin on new parts, which in the base case was assumed to be $70 \%$ higher than for reuse parts. Hauser and Lund (2003) show that, when remanufacturing has equal-to-new quality, profits are not lower but higher for reuse.

Results are presented in Fig. 6, where we lower the additional margin of new parts compared to reused parts from $70 \%$ to $-70 \%$. Because reuse is not applied in sc. 5 we only analyse sc. 7 . The less profitable new production, the more profitable scenario 7 due to reuse. Note that in sc.7, we always apply reuse, even if new production is more profitable. The relationship is linear because option 1 is first in time and NPV changes equal actual value of money.

We should remember that the viability of reuse also depends on scrap prices as much as new parts sales. It is realistic to assume rising energy and material prices in the near future. This in turn makes options 2 and 3 more profitable. So therefore we conduct sensitivity analysis on these variables in the next section. Both scenarios 7 and 5 are interesting from this point of view.

\subsection{Sensitivity analyses on scrap prices}

Revenues are raised by $10-90 \%$ for options 2 and 3 and optimality is checked for two scenarios. Scenario 7 is split into a conservative sub-scenario where parts reuse has equal margin to new ones and a sub-scenario with a $50 \%$ margin increase over new parts. Of course we can see that total profits soar with increasing revenues from scrapping materials. We have also looked at the temptation to skip again reuse, in other words revert from scenarios 7 to 5 because of immediate profits. This only happens when scrap prices increase more than $50 \%$ and only for the case where new and reuse parts have the same margin.

We argue that in the future this will not likely be the case, provided that reuse can meet the equal-to-new quality requirement reuse by remanufacturing. Figure 7 gives the results.

\subsection{Sensitivity analysis on recovery feasibility}

From here onwards decisions optimized are no longer Boolean, but we allow for fractional allocation. We carry out sensitivity analysis in $\gamma, \mu$, and $\mathrm{k}$ for the case of three loops, first independently and then combined. We assume no cannibalization because of remanufacturing and equal
Fig. 5 Sensitivity on primary market cannibalization for scenario 7 (and 5)

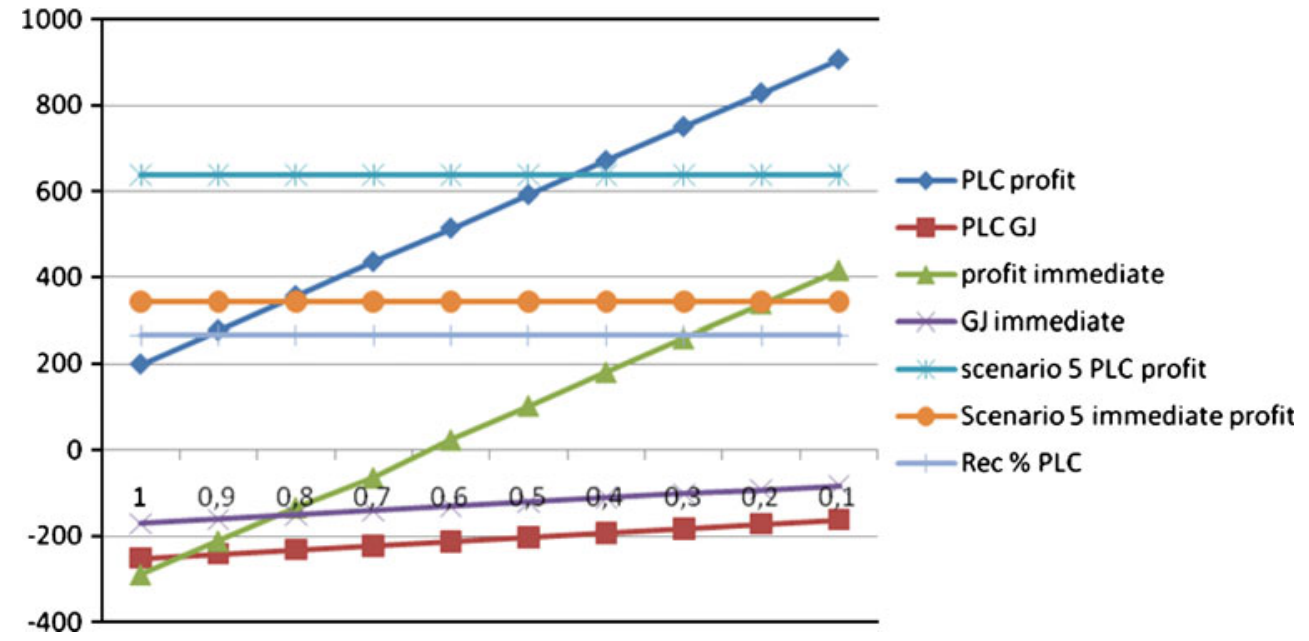


Fig. 6 Varying margin on new parts production, scenario 7

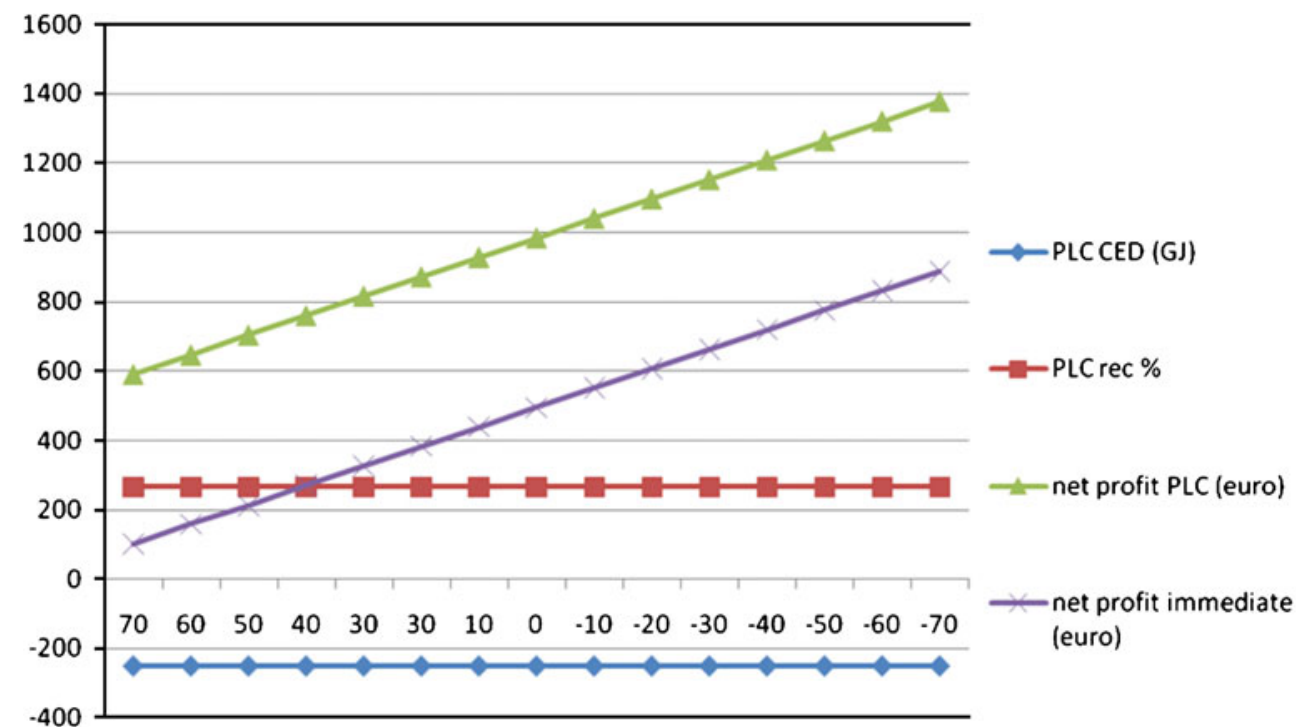

margins on reused and new parts. Option 1 has $495 €$, option 2 has $344 €$, and option 3 has $393 €$ immediate net profits.

One can derive from Fig. 8 that reducing individual feasibility factors reduces profit in a semi-linear fashion, but a leverage effect exists when all three go down simultaneously. Because energy and material (re-) use have no time-based value, the effects here are linear. But also creating environmental benefits depend heavily on creating multiple loops and hence on recovery feasibility.

Figure 9 shows the contribution of loops to profit. As feasibility reduces later options ( 2 and 3 ) are pulled into the first loop (earlier in time), which becomes vulnerable to decreased feasibility of all three options; causing convex curves for loop 1. The same effect applies to loop 2 but to a lesser extend. Loop 2 also suffers from reduced input volume coming from loop 1. Loop 3 is sucked out by the previous two loops fast at the start of the curve, after that there is not so much left for loop 3 and profits decrease in a concave fashion. Note that we assume that infeasible fractions are processed outside our system and incur neither profits nor cost, at least for the system at hand. Although variables are optimized and not preset as a Boolean, optimal solutions come very close to scenario 7 .

\subsection{Sensitivity on legislative targets}

Another issue is how governments can help to create multiloop systems. Table 4 shows some examples of recovery quota currently applied in most directives around the world. As mentioned, the literature shows that many EPR systems, including the Dutch system, focus on low level recycling and incineration, in this study defined as option 3 (Zoeteman et al. 2010). The relatively high feasibility of option 3 (being the least demanding in terms of input) makes it tempting for practitioners to prefer this option as it is relatively easy to implement.

In this paragraph, we want to show the risks of taking such an approach concerning compliance as well as the amount of money lost over the product life cycle.
Fig. 7 Sensitivity analysis on scrap prices increase scenario 7 (and 5)

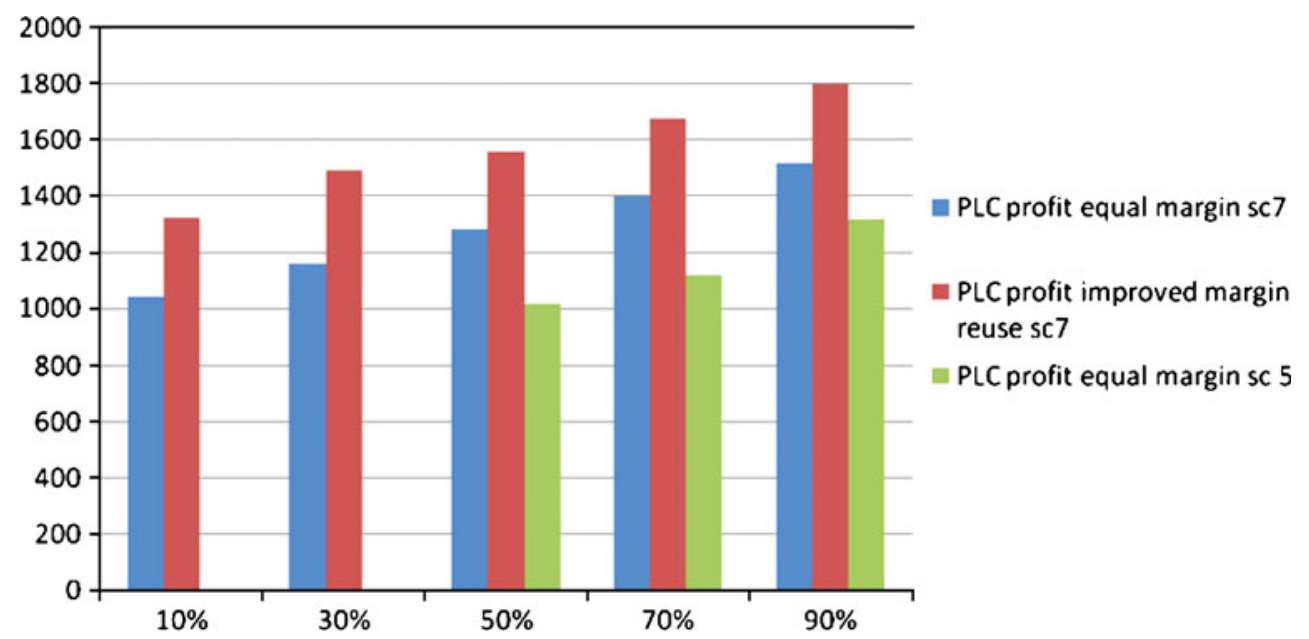


Fig. 8 Results with decreased feasibilities $\gamma, \mu$, and $\mathrm{k}$

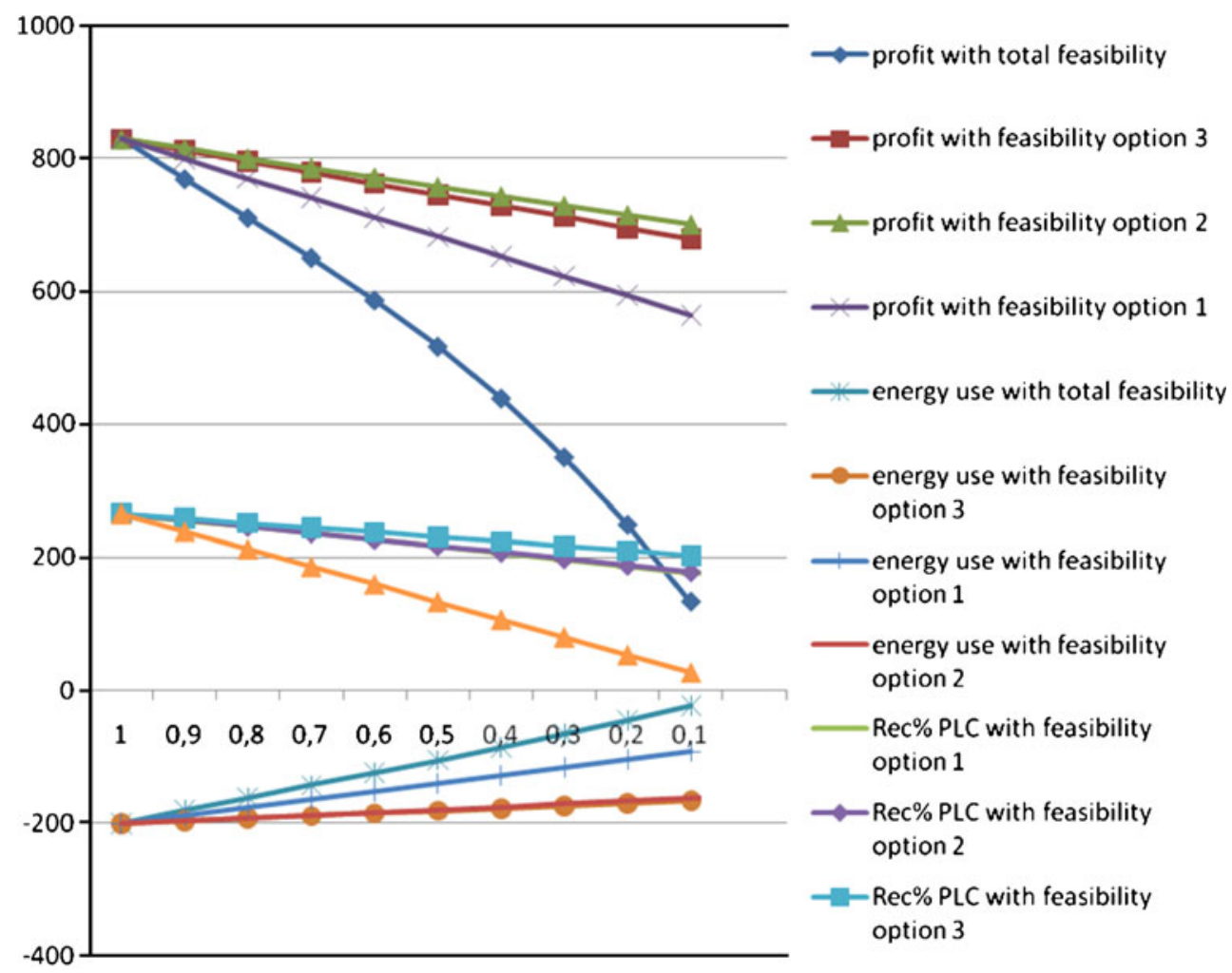

For our analysis we define two targets; T1 defines the minimum amount of recovery for of option 1 and option 2 combined. Target T2 sets a minimum quota for all options together. Note that some countries only define T2. We calculate results for one loop only, but allow for multiple options in the optimization model and then compare results with a single option 3 . On the $x$-axis of Fig. 10 , one sees feasibility of options, where we set $\gamma=0,9 \mu=0,8 \mathrm{k}$, (values of the latter are printed). On the $y$-axis we print recovery scores $\%$ for $\mathrm{T} 1$ and $\mathrm{T} 2$, net profits of both options and the footprints in CED reduction and PLC recovery percentage. However, the results show that with decreasing feasibility the multi-option approach is more robust to meeting the targets. Based on current and expected regulation worldwide, it is reasonable to set target $\mathrm{T} 2$ at $90 \%$. The T2 score for multi-option drops below this value when feasibility drops below $0.4(0.3,0.2$, respectively). Moreover, it is shown that the multi-option approach is not only more robust to compliance but also footprints and profits are better, even in this single-loop example.

So far, we only discussed one loop. But that allowing for multiple options, automatically allows for multi-loop solutions. However, it is confirmed that reduced feasibility of options diminishes life cycle benefits.
Fig. 9 Contribution of loops to profit with reduced total feasibility, $\gamma, \mu$, and $\mathrm{k}$ simultaneously

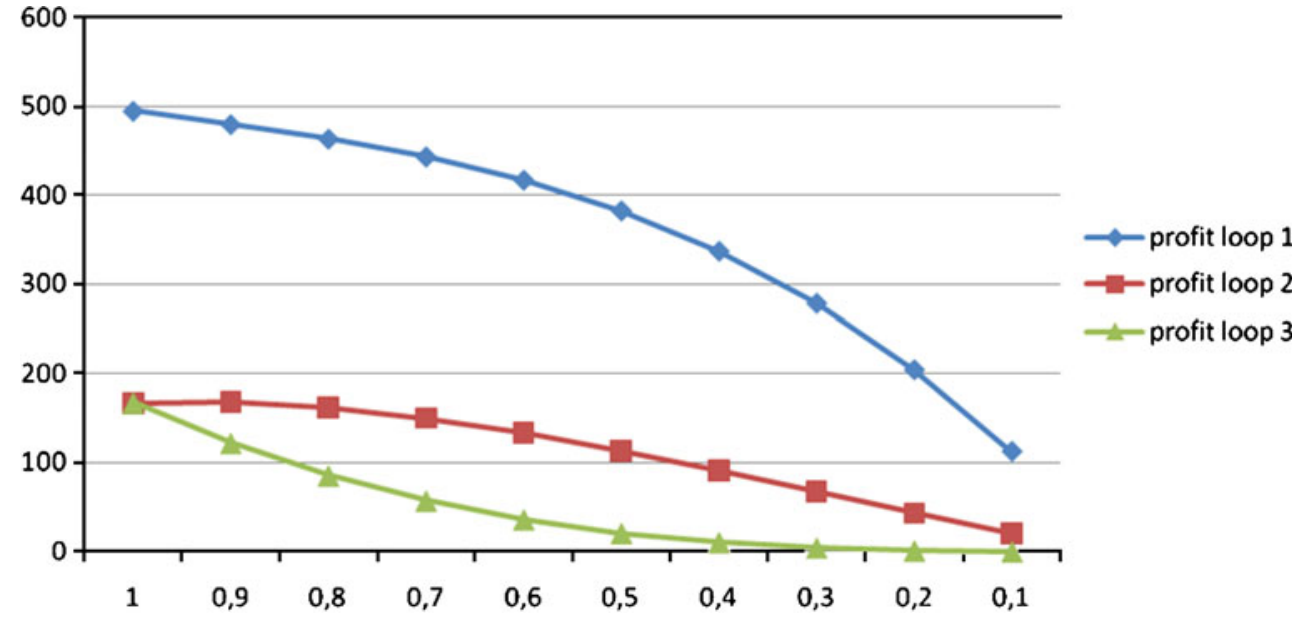


Table 4 Recovery quota 2008 (2015)

\begin{tabular}{llll}
\hline Scope & EU & Japan & Korea \\
\hline Recovery & $85 \%(95 \%)$ & $30 \%(70 \%)$ & $85 \%(95 \%)$ \\
Reuse and recycling & $80 \%(85 \%)$ & & \\
\hline
\end{tabular}

\subsection{Discussion}

Compared to the findings in the literature, our results in terms of economical and environmental performance are more spectacular, due to the multi-loop approach. The trade-off between eco(nomical) and eco(logical) performance also add value to the literature as well as the inclusion of time-based value of money. The results might even be stronger if we include product design aspects.

Based on the results we can formulate the following insights for industry. First, cascade markets for reuse may appear attractive but when cannibalizing on new sales, margins are compromised. Instead, returns should be a source of equal-to-new parts and no visible difference should exist between new and recovered ones. Companies must suppress their natural instincts of maximizing short term profits and delay some of the revenues by implementing multi-loop models. The environment benefits as well. This requires that all loops are controlled well (by industry) and returns should not end up in grey circuits outside the system.

Feasibility of returns should be maximized which for example implies careful collection and storage of wrecks, preventing damage and corrosion. Product design changes may further enhance recoverability. In today's practice, often $\mathrm{K}$ is often upgraded virtually by governments by allowing for doubtful "recovery" options. For example, each car wreck contains about $25 \mathrm{k}$ of sand which is buried in the ground. Today, this is counted as reuse under T2, and hence the $95 \%$ target is met. In the opinion of the author it is just an alternative way of landfill. It does certainly not improve footprints.
Additional advices to the governments apply. As mentioned, most EPR based systems in place today maximize single loop 3 due to quota based targets. Using different steering principles could stimulate multi-loop solutions that prove more robust, more profitable and have better footprint. For example, not charging VAT on remanufactured parts improves their margin and hence immediate profits if this option for those industries that are not capable of taking a PLC perspective. Charging environmental taxes on new production or total energy use (CED) may further strengthen the relative competitive position of recovery.

\section{Conclusions}

This paper studies decision making in recovery, comparing opportunistic decision making with short term optimizing versus a life cycle perspective. After comparing the problem with know how in the literature a model was presented optimizing NPV of revenues and subsequently calculating environmental impact by two indicators.

The model was applied in a real-life case with realistic data. It was found that indeed applying multiple loops over the life cycle is most viable and beneficial to the environment as well, but that a short term focus may hinder this strategy. It was discussed how businesses can remove barriers in order to adopt such a life-cycle-based approach and how government directives and other policy measure can help in this.

The study is limited to the current situation as we fail data on for instance changing vehicles and/or new recovery technologies. It is limited to three loops although in practice more is possible. We assume that all loops are under control of one actor, in reality this is not very often the case. Moreover, a priori choices in choosing performance indicators, in particular for environmental impact, may bias results. Further research on this must be conducted to verify
Fig. 10 Sensitivity to EU targets as a function of feasibility

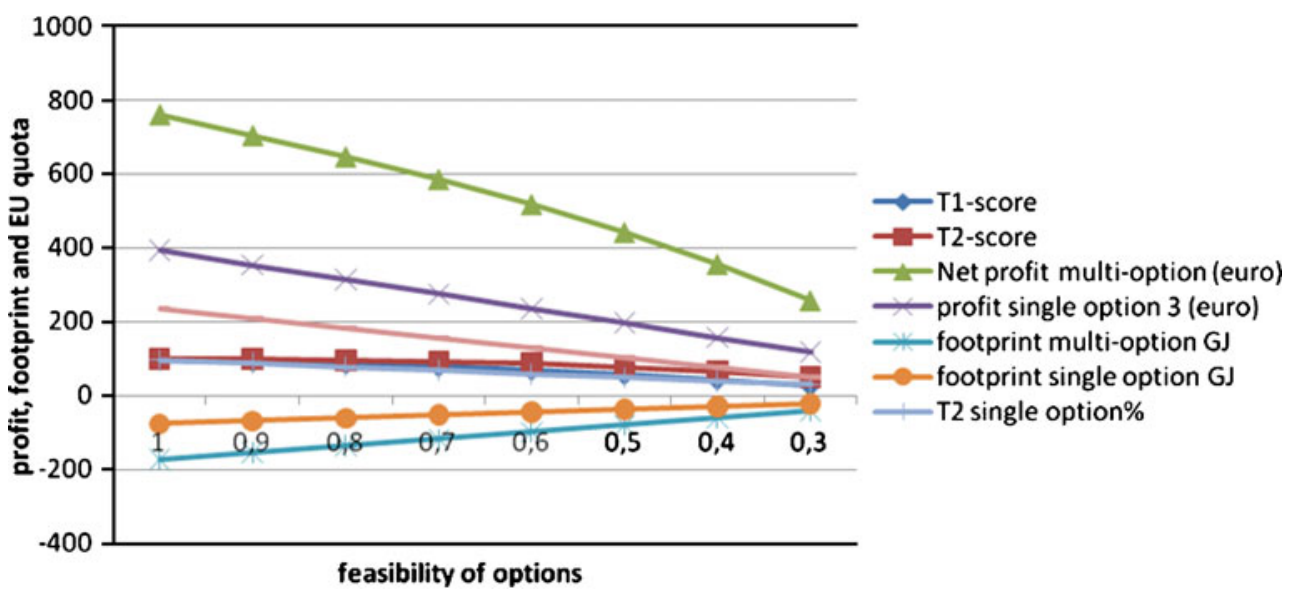


results as well as additional case studies. Data collection from practice must be improved because we cannot rely on generic LCA databases alone. We must also study more managerial areas, in particular with respect to business models and enforcement of (EPR) policies in order to make multi-loop recovery practically feasible.

Open Access This article is distributed under the terms of the Creative Commons Attribution Noncommercial License which permits any noncommercial use, distribution, and reproduction in any medium, provided the original author(s) and source are credited.

\section{References}

Bloemhof-Ruwaard JB, Van Wassenhove LN, Gabel HL, Weaver PM (1996) Environmental life-cycle optimization model for the European pulp and paper industry. Omega 24(6):615-629

Castro MBG, Remmerswaal JAM, Reuter IM (2003) Life cycle impact assessment of the average passenger vehicle, in the Netherlands. Int J LCA 8(5):297-304

Ferrao P, Amaral J (2006) Assessing the economics of auto recycling activities in relation to European Union Directive on EOL vehicles. Techn forecast and soc change 73:277-289

Fleischer G, Gerner K, Kunst H, Lichtenvort K, Rebitzer G (2001) A semi-quantitative method for the impact assessment of emissions within a simplified life cycle assessment. Int J LCA 6(3):149-156

Gehin A, Zwolinski P, Brissaud D (2008) A tool to implement sustainable end-of-life strategies in the product development phase. J Clean Prod 16:566-576

Guide D, Van Wassenhove LN (2001) Managing product returns for remanufacturing. Prod Oper Manag 10(2):142-154

Gungor A, Gupta SM (1999) Issues in environmentally conscious manufacturing and product recovery: a survey. Comput Ind Eng 36:811-853

Hammond D, Beullens P (2007) Closed-loop supply chain network equilibrium under legislation. Eur J Oper Res 183(2):895-908

Hauser W, RT Lund (2003) The remanufacturing industry: anatomy of a giant. A view of remanufacturing in America based on a comprehensive survey across the Industry. Technical paper, Department of Manufacturing Engineering, Boston University, Massachusetts

Huijbregts MAJ, Rombouts LJA, Hellweg S, Frischknegt R, Hendriks AJ, Van der Meent D, Ragas AMJ, Reijnders L, Struijs J (2006) Is cumulative fossil energy demand a useful indicator for the environmental performance of products? Environ Sci Technol 40(3):641-648

Hula A, Jalali K, Skerlos SJ, Saitou K (2003) Multi-criteria decision making for optimization of product disassembly under multiple situations. Environ Sci Technol 37:5303-5313

Hunt R, Boguski T, Weitz K, Sharma A (1998) Case Studies Examining LCA Streamlining Techniques. Int J LCA 3(1):36-42

Iakovou E, Moussiopoulos N, Xanthopoulos A, Achillas C, Michailiddis N, Chatzipanagioti M, Koroneos C, Bouzakis KD, Kikis V (2009) A methodological framework for end-of-life management of electronic products. Resour Conservat Recycl 53:329-339

Ilgin MA, Gupta SM (2010) Environmentally conscious manufacturing and product recovery: a review of the state of the art. J Environ Manag 91:563-591
Kerr W, Ryan C (2001) Eco-efficiency gains from remanufacturing: a case study of photocopier remanufacturing at Fuji Xerox Australia. J Clean Prod 9:75-81

Krikke HR, van Harten A, Schuur PC (1998) On a medium term product recovery and disposal strategy for durable assembly products. Int J Prod Res 36(1):111-139

Krikke HR, Bloemhof-Ruwaard J, Van Wassenhove LN (2003) Concurrent product and closed-loop supply chain design with an application to refrigerators. Int J Prod Res 41(16):36893719

Lambert AJD (2003) Disassembly sequencing: a survey. Int J Prod Res 41(16):3721-3759

Le Blanc HM (2006) Closed-loop supply chains management: designing reverse supply chains for end-of-life vehicles. Dissertation CentER, nr.160, Tilburg University

Mayers K (2001) An investigation of the implications and effectiveness of producer responsibility for the disposal of WEEE. Dissertation, Brunel University

Michelsen O, Magerholm Fet A, Dahlsrud A (2007) Eco-efficiency in extended supply chains: a case study of furniture production. J Environ Manag 79:290-297

OECD (2001). Proceedings of OECD seminar on extended producer responsibility, 13-14 December 2001, Paris, France

Quariguasi Frota Neto J, Bloemhof-Ruwaard JM, van Nunen JAEE, van Heck HGWM (2008) Designing and evaluating sustainable logistic networks. Int J Prod Econ 111(2):195-208

Quariguasi Frota Neto J, Walther G, Bloemhof J, Van Nunen JAEE, Spengler Th (2009) A methodology for assessing eco-efficiency in logistics networks. Eur J Oper Res 193:670-682

Schmidt WP, Dahlqvist E, Finkbeiner M, Krinke S, Lazzari S, Oschmann D, Pichon S, Thie C (2004) Life cycle assessment of lightweight and end-of-life scenarios for generic compact class passenger vehicle. Int J LCA 9(6):405-416

Schultman F, Zumkeller M, Rentz O (2006) Modelling reverse logistics tasks within closed-loop supply chains: an example from the automotive industry. Eur J Oper Res 171:1033-1050

Spengler Th, Ploog M, Schroter M (2003) Integrated planning of acquisition, disassembly and bulk recycling: a case study on electronic scrap recovery. OR Spectr 25(3):413-442

Spielmann M, Althaus HJ (2007) Can prolonged use of a passenger car reduce environmental burdens? LCA of Swiss passenger cars. J Clean Prod 15:1122-1144

Srivastava SK (2007) Green supply chain management: a state-of-theart review. Int J Manag Rev 9(1):53-80

Staikos T, Rahimifard S (2007) An end-of-life descision support tool for product recovery considerations in the footwear industry. Int J Comput Integrated Manuf 20:602-615

Thierry M, Salomon M, van Nunen JAEE, Van Wassenhove LN (1995) Strategic issues in product recovery management. Calif Manage Rev 37(2):114-135

Van der Laan EA (2003) An NPV and AC analysis of a stochastic inventory system with joint manufacturing and remanufacturing. Int J Prod Econ 81-82:317-331

Williams JAS, Wongweragiat S, McGlinch JB, Bonawi-tan W, Choi JK, Schiff J (2007) An automotive bulk recycling planning model. Eur J Oper Res 177:969-981

Zoeteman B, Krikke HR, Venselaar J (2010) Handling WEEE waste flows: on the effectiveness of producer responsibility in a globalizing world. Int J Adv Manuf Syst 47:415-436

Zuidwijk R, Krikke HR (2008) Strategic response to the WEEE-directive: product eco-design or new recovery processes? Eur J Oper Res 191:1206-1222 